\title{
Avaliação do desempenho e da qualidade dos ovos de codornas de corte de dois grupos genéticos
}

\author{
Carlos Henrique Rocha Costa $^{1}$, Sergio Luiz de Toledo Barreto ${ }^{2}$, Roque Machado de Mesquita \\ Filho $^{1}$, Marcelle Santana de Araujo ${ }^{1}$, Regina Tie Umigi ${ }^{1}$, Heder José D'Avila Lima ${ }^{1}$
}

\footnotetext{
${ }^{1}$ Pós-graduação em Zootecnia, da Universidade Federal de Viçosa.

2 Universidade Federal de Viçosa - Departamento de Zootecnia, s/n - Campus Universitário - Viçosa - MG.
}

RESUMO - Conduziu-se um experimento com o objetivo de avaliar o desempenho e a qualidade dos ovos de codornas de corte de dois grupos genéticos durante 84 dias de experimento. Utilizaram-se 98 aves com média de peso equivalente a 258 g e 40 dias de idade, distribuídas em delineamento inteiramente casualizado com dois grupos genéticos (A e B) e sete repetições de sete aves por unidade experimental. Foram avaliados o consumo de ração (g/ave/dia), o peso médio dos ovos (g), a postura por ave por dia (\%) e por ave alojada (\%), a porcentagem de ovos viáveis produzidos, a porcentagem de ovos viáveis/ave/dia, a massa de ovos (g/ave/dia), a conversão por massa de ovos (kg/kg), a conversão por dúzia de ovos (kg/dz), a gravidade específica $\left(\mathrm{g} / \mathrm{cm}^{3}\right)$, o peso da gema (g), do albúmen e da casca, a porcentagem de gema, albúmen e casca, a altura e o diâmetro dos ovos (mm), a viabilidade das aves (\%), o peso inicial e final (g) e o ganho de peso (g) das aves. O grupo genético B apresentou menor peso inicial aos 40 dias de idade, maior peso e porcentagem de casca e melhor gravidade específica dos ovos. As demais características não diferiram entre os grupos genéticos. Ambos os grupos genéticos avaliados apresentam desempenho satisfatório no período de 40 a 124 dias de idade.

Palavras-chave: Coturnix coturnix coturnix, linhagem, peso corporal, postura, produção

\section{Evaluation of performance and egg quality of two genetic group of meat quails}

\begin{abstract}
An experiment was conducted with the objective to evaluate the performance and quality of eggs from meat quails from two genetic groups during 84 days of experiment. A total of 98 birds averaging $258 \mathrm{~kg}$ and 40 days old was assigned to a completely randomized design with two genetic groups (A and B) and seven replications of seven birds each. The evaluated characteristics were: diet consumption (g/bird/d), average egg weights (g), laying per bird per day (\%) and per lodged bird (\%), percentage of viable eggs produced, percentage of viable eggs/bird/d, egg mass (g/bird/d), conversion by egg mass $(\mathrm{kg} / \mathrm{kg})$, conversion by egg dozen $(\mathrm{kg} / \mathrm{dz})$, specific gravity $\left(\mathrm{g} / \mathrm{cm}^{3}\right)$, egg yolk weight $(\mathrm{g})$, albumen and shell, percentage of yolk, albumen and shell, height and diameter of eggs (mm), viability of birds (\%), initial and final weight (g) and weight gain (g). The genetic group B showed lower initial weight at 40 days old, higher weight and percentage of shell and better specific gravity of eggs. The other characteristics did not differ between the genetic groups. Both evaluated genetic groups have satisfactory performance in the period from 40 to 124 days old.
\end{abstract}

Key Words: body weight, Coturnix coturnix coturnix, laying, production, strain

\section{Introdução}

A prática da criação de codornas para abate no Brasil é recente. A sub-espécie mais difundida no País ainda é a Coturnix coturnix japonica, linhagem de baixo peso corporal, utilizada para a produção de ovos para consumo. Hoje, já se observa no Brasil um tipo de codorna mais pesada, que atende aos quesitos necessários à produção de carne. Estas apresentam maior peso vivo (250 a 300 g), coloração marrom mais viva, temperamento nitidamente calmo e peso e tamanho dos ovos um pouco maior (Oliveira, 2001).
Atenta ao consumidor, a Perdigão ${ }^{\circledR}$, empresa do setor avícola, introduziu no Brasil uma nova variedade de codornas para produção de carne, que, aos poucos, foi denominada pelos produtores de linhagem italiana (Móri et al., 2005a). De acordo com Almeida (2001), os machos da linhagem italiana apresentam boa aptidão para corte, apresentando melhor desempenho que os da linhagem japonesa, caracterizando-se por maior ganho de peso e melhor conversão alimentar. Segundo esse autor, as codornas italianas são superiores às codornas japonesas em relação ao ganho de peso semanal, porém fêmeas da linhagem japonesa apresen- 
tam maior precocidade para postura do primeiro ovo que fêmeas da linhagem italiana.

A exploração da codorna para corte ainda é pequena e deve aumentar muito vagarosamente, devido à falta de hábito do consumidor por este tipo de carne, além do preço, que é elevado. Apesar disso, percebem-se aumentos na apreciação da carne e no consumo. As carcaças pesam cerca de 176 g e a idade ótima de abate se dá em torno de 6 semanas de idade das aves. Os trabalhos científicos indicam rendimento de carcaça de $72 \%$ e os trabalhos de seleção já mostram a existência de aves pesando em torno de $260 \mathrm{~g}$ no abate (Móri et al., 2005b).

A genética tem sido estudada para aumentar o peso ao abate, melhorar a eficiência alimentar e especialmente a viabilidade dessas aves. Entretanto, o material genético existente no Brasil precisa ser melhorado, o que poderá ser realizado somente com a elaboração de programas de melhoramento genético eficazes, que visem à obtenção de linhagens definidas. Também é necessário que os matrizeiros sejam de excelente qualidade mantenham em suas granjas lotes controlados e linhagens selecionadas com bases científicas e econômicas e realizem com freqüência a renovação do material genético, por intermédio da importação de aves ou ovos, de modo a manter adequada variabilidade genética que resulte em qualidade bastante satisfatória de seus produtos.

Segundo Móri et al. (2005a), os pesquisadores têm buscado melhor conhecimento das linhagens disponíveis, a fim de se estabelecer índices zootécnicos, contribuindo para o pleno desenvolvimento da criação. Dessa forma, objetivou-se avaliar o desempenho e a qualidade dos ovos de codornas de corte de dois grupos genéticos.

\section{Material e Métodos}

Foram utilizadas 98 codornas européias, fêmeas, com 40 dias de idade, metade do grupo genético A e a outra metade do grupo genético $\mathrm{B}$. As aves foram provenientes de dois grupos genéticos (A e B) em estudo na granja de melhoramento da Universidade Federal de Viçosa.

As aves foram criadas em condições idênticas de manejo e alimentação até os 40 dias de idade, quando se iniciou o período experimental, que teve duração de 84 dias, divididos em quatro ciclos de 21 dias. Aos 28 dias, as fêmeas foram alojadas em gaiolas metálicas, apropriadas para produção de ovos. A bateria era composta de cinco gaiolas (andares) de arame galvanizado, cada uma com três unidades experimentais com dimensões de $32 \times 37 \times 16 \mathrm{~cm}$ (largura $\times$ profundidade $\times$ altura). Em cada unidade experimental, foram alojadas sete aves, em densidade de $169 \mathrm{~cm}^{2} /$ ave. Sob o piso das gaiolas, foi colocada uma bandeja de chapa metálica galvanizada encapada com plástico para recolhimento das excretas. As gaiolas foram equipadas com comedouros e bebedouros lineares, ambos percorrendo toda a extensão da gaiola: o comedouro posicionado na parte frontal e o bebedouro, na parte posterior da gaiola. Cada comedouro foi equipado com divisórias de madeira, coincidindo com a largura de cada unidade experimental.

A partir da primeira semana de alojamento, foi iniciado o programa de luz, com 14 horas diárias de fotoperíodo e aumentos sucessivos de 30 minutos semanais até obtenção de 17 horas diárias. As aves receberam ração e água à vontade durante todo o período experimental (a ração fornecida duas vezes ao dia). Semanalmente, as eventuais sobras de ração foram pesadas em balança eletrônica para análise do consumo por ave/dia e da conversão alimentar. Diariamente, os ovos de cada parcela foram contados e registrados em planilha apropriada.

As aves foram alimentadas durante todo o período experimental com ração única à base de milho e farelo de soja (Tabela 1), contendo $20 \%$ de proteína bruta e 2.900 kcal de EM/kg de dieta, conforme recomendações do NRC (1994) para codornas em postura, exceto para o nível de cálcio (3,2\%), conforme recomendado por Barreto et al. (2007).

A temperatura e a umidade relativa foram monitoradas duas vezes ao dia, às 8 e 16h, por meio de termômetros de máxima e mínima e de bulbo seco e úmido, posicionados no centro da instalação.

Foram avaliados o consumo de ração/ave/dia (g), o peso médio dos ovos (g), a postura por ave/dia (\%) e por ave alojada (\%), a porcentagem de ovos viáveis produzidos, a porcentagem de ovos viáveis por ave/dia, a massa de ovos (g/ave/dia), a conversão por massa de ovos (kg/kg), a conversão por dúzia de ovos (kg/dz), a gravidade específica $\left(\mathrm{g} / \mathrm{cm}^{3}\right)$, o peso da gema (g), do albúmen (g) e da casca (g), a porcentagem de gema, de albúmen e de casca, a altura e o diâmetro dos ovos (mm), a viabilidade (\%), o peso inicial e final (g) e o ganho de peso das aves (g).

Para determinação do número médio de ovos viáveis (comercializáveis), durante os 84 dias experimentais, foram computados diariamente nesta categoria o número de ovos quebrados, com casca mole e sem casca, para determinação da perda de ovos de cada unidade experimental (UE). As variáveis foram analisadas com suas respectivas fórmulas: porcentagem de ovos viáveis produzidos ( $\left(\mathrm{n}^{\circ}\right.$ total de ovos viáveis produzidos por $\mathrm{UE}) /\left(\mathrm{n}^{\circ}\right.$ total de ovos produzidos) $\times 100)$ e produção de ovos viáveis por ave-dia ((tx de 
Tabela 1 - Composição percentual e química da ração experimental na matéria natural

\begin{tabular}{|c|c|}
\hline Ingrediente & Quantidade (\%) \\
\hline Milho & 51,064 \\
\hline Farelo de soja & 34,824 \\
\hline Óleo de soja & 4,413 \\
\hline Calcário & 7,215 \\
\hline Fosfato bicálcico & 1,332 \\
\hline L-lisina $\mathrm{HCl}$ (79\%) & 0,155 \\
\hline L-treonina (98\%) & 0,047 \\
\hline DL-metionina (99\%) & 0,345 \\
\hline Sal & 0,335 \\
\hline Suplemento vitamínico ${ }^{1}$ & 0,100 \\
\hline Suplemento mineral ${ }^{2}$ & 0,050 \\
\hline Antioxidante $^{3}$ & 0,010 \\
\hline Cloreto de colina & 0,100 \\
\hline Total & 100,000 \\
\hline \multicolumn{2}{|l|}{ Composição calculada } \\
\hline EM (kcal/kg) & 2900 \\
\hline PB (\%) & 20,000 \\
\hline Metionina (\%) & 0,485 \\
\hline Metionina + cistina (\%) & 0,797 \\
\hline Lisina (\%) & 1,170 \\
\hline Treonina (\%) & 0,730 \\
\hline Triptofano (\%) & 0,230 \\
\hline $\mathrm{Ca}(\%)$ & 3,200 \\
\hline P disponível (\%) & 0,350 \\
\hline $\mathrm{Na}(\%)$ & 0,150 \\
\hline \multicolumn{2}{|c|}{ 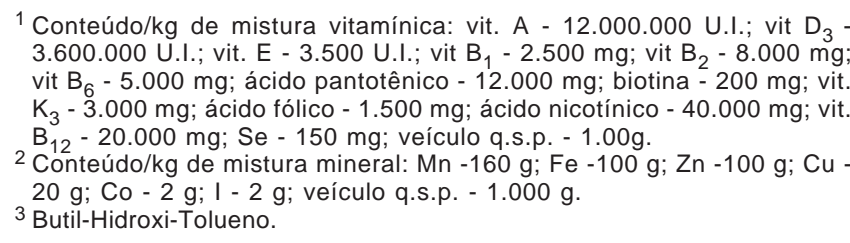 } \\
\hline
\end{tabular}

postura (\%) $\times$ total de ovos viáveis) / ( $\mathrm{n}^{\circ}$ total de ovos produzidos)).

Os ovos de cada parcela foram pesados semanalmente durante três dias consecutivos. A cada 21 dias, por 6 dias consecutivos foi recolhida ao acaso, nos 3 últimos dias, uma amostra de 4 ovos de cada parcela para avaliação do peso e das porcentagens de gema, albúmen e casca e, nos 3 primeiros dias, todos os ovos íntegros coletados foram submetidos à avaliação de sua gravidade específica.

Os parâmetros avaliados foram submetidos a análise de variância a 5\% de probabilidade utilizando-se o Programa SAEG - Sistema para Análises Estatísticas e Genéticas UFV (2004). Aplicou-se o teste F utilizando-se como nível de rejeição alfa igual a 0,05.

\section{Resultados e Discussão}

A temperatura máxima obtida foi de $23,7 \pm 2,3^{\circ} \mathrm{C}$ e a mínima de $19,5 \pm 3,1^{\circ} \mathrm{C}$. A umidade relativa foi de $79,4 \pm 1,8 \%$.

Verificou-se diferença significativa $(\mathrm{P}<0,01)$ para peso corporal aos 40 dias de idade entre os grupos genéticos
(Tabela 2). No entanto, a idade ao primeiro ovo foi de 39 dias para ambos os grupos genéticos, sendo que o grupo genético A alcançou $50 \%$ de postura aos 53 dias e o grupo B aos 54 dias de idade. Não houve diferença $(\mathrm{P}>0,05)$ entre os grupos genéticos A e B quanto à produção (ovo/ave/dia, ovo ave-alojada e ovo viável/ave/dia), à massa de ovo, à conversão por massa e por dúzia de ovos, ao peso final, ao ganho de peso e à viabilidade das aves, portanto, apesar da seleção genética das aves do grupo A para maior peso corporal, essas aves consumiram em média a mesma quantidade de ração que as aves do grupo genético B. Apesar de as aves do grupo A terem atingido peso 1,7\% superior aos 40 dias de idade, com o decorrer do experimento, foram diminuindo o seu ritmo de ganho de peso, em comparação às aves do grupo genético $\mathrm{B}$. Embora a genética não tenha influenciado $(\mathrm{P}>0,05)$ a viabilidade das aves, em valores absolutos, a taxa de sobrevivência das aves do grupo B (mais leves na maturidade sexual) foi 10,43\% superior à das codornas do grupo genético A.

Os resultados obtidos para produção de ovos corroboram aqueles verificados por Móri et al. (2005a), em pesquisa com codornas de corte de quatro grupos genéticos, distintos dos grupos utilizados neste experimento, no qual também se observou ausência de diferença estatística entre os quatro grupos, embora dois deles tenham apresentado discreta tendência de superioridade na porcentagem média de produção em relação aos outros dois grupos. O mesmo foi obtido por Altan et al. (1998), que não encontraram diferenças significativas na produção de ovos de linhagens selecionadas para alto ganho de peso em sua pesquisa.

No entanto, Marks (1979), Anthony et al. (1990), Piccinin (2002) e Minvielle et al. (2002) obtiveram diferenças significativas para produção de ovos entre linhagens. Segundo Móri et al. (2005a), a variabilidade genética entre as aves utilizadas nas pesquisas pode ser a explicação para a diferença entre os resultados obtidos na literatura.

Resultados diferentes dos encontrados neste experimento foram obtidos por Móri et al. (2005a), ao analisarem a massa de ovos. Esses autores observaram diferenças estatísticas entre os grupos genéticos, com maiores valores para o grupo B.

Trabalhando com linhagens selecionadas para corte e para postura, Singh \& Panda (1987) relataram em sua pesquisa que a linhagem selecionada para produção de carne apresentou massa de ovos superior à de linhagens selecionadas para produção de ovos.

O consumo médio de ração por ave/dia e a conversão alimentar por massa e por dúzia de ovos não foram influenciados pelos grupos genéticos $(\mathrm{P}>0,05)$. Diversos autores encontraram resultados divergentes (Murakami et al., 1993; 
Tabela 2 - Desempenho de dois grupos genéticos de codornas de corte

\begin{tabular}{|c|c|c|c|c|c|}
\hline \multirow[t]{2}{*}{ Variável } & \multicolumn{2}{|c|}{ Grupo genético } & \multirow[t]{2}{*}{ Média } & \multirow[t]{2}{*}{ CV (\%) } & \multirow[t]{2}{*}{ Valor de $\mathrm{P}$} \\
\hline & A & $\mathrm{B}$ & & & \\
\hline Consumo de ração (g) & 32,83 & 32,89 & 32,86 & 3,55 & NS \\
\hline Ovos/dia (\%) & 73,87 & 76,10 & 74,99 & 7,10 & NS \\
\hline Ovos/ave alojada (\%) & 69,51 & 75,07 & 72,29 & 11,46 & NS \\
\hline Ovos viáveis (\%) & 97,91 & 98,65 & 98,28 & 0,99 & NS \\
\hline Ovos viáveis ave/dia (\%) & 72,35 & 75,11 & 73,73 & 7,68 & NS \\
\hline Massa de ovos (g) & 9,65 & 9,99 & 9,82 & 6,79 & NS \\
\hline Conversão massa de ovos (kg/kg) & 3,426 & 3,297 & 3,362 & 7,82 & NS \\
\hline Conversão dúzia de ovos (kg/dz) & 0,536 & 0,521 & 0,529 & 8,86 & NS \\
\hline Peso inicial (g) & $260,28 a$ & $255,85 b$ & 258,07 & 0,73 & $* *$ \\
\hline Peso final (g) & 347,11 & 346,78 & 346,95 & 2,68 & NS \\
\hline Ganho de peso (g) & 86,83 & 90,93 & 88,88 & 11,10 & NS \\
\hline Viabilidade (\%) & 87,74 & 97,96 & 92,85 & 10,63 & NS \\
\hline
\end{tabular}

** Efeito significativo $(P<0,01)$; NS - Não-significativo $(P>0,05)$.

Masukawa et al., 2001; Piccinin, 2002; Móri et al., 2005a), o que pode ser explicado, segundo Móri et al. (2005a), pelos níveis nutricionais fornecidos às aves, pelas diferenças entre os grupos genéticos e pelas aptidões das aves, uma vez que esses autores estudaram linhagens especializadas para produção de ovos, as quais apresentam menor consumo de ração em comparação àquelas especializadas para produção de carne.

Móri et al. (2005a), estudando quatro grupos genéticos de codornas para produção de carne, registraram pior conversão alimentar ( 3,77 a 3,98 para massa de ovos e 0,58 a 0,60 para dúzia de ovos) em comparação aos resultados obtidos neste estudo. Isto pode ser explicado pelas diferenças entre os grupos genéticos utilizados em cada ensaio, além do período experimental prolongado.

Não foi constatado efeito significativo $(P>0,05)$ de ambos os grupos genéticos para viabilidade, que, na maioria das vezes, foi atribuída a causas desconhecidas, portanto, não foi constatado nenhum caso de morte por prolapso do oviduto das aves. O mesmo resultado foi obtido por Móri et al. (2005a) ao avaliarem a mortalidade das aves. Entretanto, esses pesquisadores observaram alguns casos de morte por prolapso do oviduto.

Os grupos genéticos não influenciaram significativamente $(\mathrm{P}>0,05)$ o peso dos ovos, o peso e a porcentagem da gema, o peso e a porcentagem do albúmen e a altura e o diâmetro dos ovos (Tabela 3). Houve efeito significativo $(\mathrm{P}<0,05)$ para a gravidade específica e o peso e a porcentagem de casca, indicando que as aves que sofreram maior pressão de seleção para ganho de peso (grupo A) produziram ovos com menor peso e porcentagem de casca, favorecendo a ocorrência de menor valor para a gravidade específica dos ovos, que foi $0,28 \%$ inferior à das aves do grupo genético $\mathrm{B}$.

Diferentemente dos resultados anteriormente citados, Móri et al. (2005a) observaram diferença significativa entre os grupos genéticos para peso dos ovos. Esses autores verificaram pesos maiores para apenas dois dos quatro em estudo. Os valores obtidos para peso do ovo apresentaram variação de 12,81 a 13,45 g entre os quatro grupos genéticos. Segundo Marks (1991), as linhagens selecionadas para alto ganho de peso apresentam maior peso dos ovos, uma vez que essa característica apresenta alta correlação com peso corporal da ave. Ricklefs \& Marks (1983), Bacon et al. (1986), Singh \& Panda (1987), Anthony et al. (1990), Altan et al. (1998), Minvielle et al. (2000) e Piccinin (2002) afirmaram que o peso médio dos ovos difere significativamente entre grupos genéticos. No entanto, apesar de os grupos genéticos não terem influenciado o peso dos ovos, neste experimento, o valor encontrado para o grupo B foi $0,6 \%$ superior ao obtido pelo grupo A.

A gravidade específica dos ovos das aves do grupo genético B foi $0,28 \%$ superior ao valor obtido pela análise dos ovos produzidos pelas aves do grupo A. Móri et al. (2005a) também observaram diferença significativa em sua pesquisa, porém apenas entre dois dos quatro grupos genéticos em estudo. Diferenças para esta variável entre grupos genéticos foram verificadas por Harms et al. (1983) e Yannakoupoulos \& Tserveni-Gousi (1986).

Os resultados obtidos para a porcentagem de gema e de albúmen estão de acordo com os encontrados por Móri et al. (2005a), que também não observaram diferenças entre os grupos genéticos para essas variáveis. O mesmo foi verificado por Singh \& Panda (1987), Anthony et al. (1990), Altan et al. (1998), e Piccinin (2002) ao trabalharem com linhagens de codornas japonesas.

Entretanto, Ricklefs \& Marks (1983), Nestor et al. (1996) e Minvielle et al. (2002) encontraram diferenças significativas para porcentagem de gema e de albúmen entre linhagens de codornas japonesas. 
Tabela 3 - Qualidade dos ovos de dois grupos genéticos de codornas de corte

\begin{tabular}{|c|c|c|c|c|c|}
\hline \multirow[t]{2}{*}{ Variável } & \multicolumn{2}{|c|}{ Grupo genético } & \multirow[t]{2}{*}{ Média } & \multirow[t]{2}{*}{ CV (\%) } & \multirow[t]{2}{*}{ Valor de $\mathrm{P}$} \\
\hline & A & $\mathrm{B}$ & & & \\
\hline Peso ovo (g) & 13,06 & 13,14 & 13,10 & 3,311 & NS \\
\hline Gravidade específica $\left(\mathrm{g} / \mathrm{cm}^{3}\right)$ & $1,071 \mathrm{~b}$ & $1,074 \mathrm{a}$ & 1,073 & 0,092 & $* *$ \\
\hline Peso de gema (g) & 3,933 & 3,987 & 3,961 & 2,328 & NS \\
\hline Peso de albúmen (g) & 8,325 & 8,300 & 8,313 & 3,639 & NS \\
\hline Peso de casca (g) & $1,021 b$ & $1,073 a$ & 1,047 & 3,805 & $*$ \\
\hline Gema (\%) & 29,61 & 29,83 & 29,72 & 1,685 & NS \\
\hline Albúmen (\%) & 62,69 & 62,13 & 62,41 & 0,873 & NS \\
\hline Casca (\%) & $7,69 b$ & $8,03 a$ & 7,86 & 2,143 & $* *$ \\
\hline Altura dos ovos (mm) & 34,10 & 33,80 & 33,95 & 0,973 & NS \\
\hline Diâmetro dos ovos (mm) & 26,46 & 26,45 & 26,46 & 1,031 & NS \\
\hline
\end{tabular}

** Efeito significativo $(P<0,01)$; * Efeito significativo $(P<0,05)$; NS - não-significativo $(P>0,05)$.

A porcentagem e o peso de casca diferiram $(\mathrm{P}<0,05)$ entre os grupos genéticos $\mathrm{A}$ e $\mathrm{B}$, cujas médias foram maiores para o grupo genético $B$ (4,2 e 4,8\%, respectivamente, superiores aos obtidos pelo grupo A). Esse resultado corrobora o encontrado por Móri et al. (2005a), que também constataram efeito significativo do grupo genético sobre a porcentagem de casca dos ovos analisados: o grupo genético de maior destaque apresentou $8,31 \%$ de casca e o de menor destaque, o valor de 7,98\%, portanto, o primeiro foi $4,0 \%$ superior ao segundo.

Outros autores (Singh \& Panda, 1987; Anthony et al., 1990; Piccinin, 2002; Minvielleetal., 2002) também registraram diferenças significativas entre as porcentagens de casca de ovos de linhagens selecionadas para produção de carne e ovos. Akbar et al. (1983) relataram que as linhagens atuais selecionadas para produção de ovos apresentam maior espessura de casca e maior resistência à quebra, como resultado da seleção para essas características.

\section{Conclusões}

Codornas de corte do grupo genético A são mais precoces e atingem maior peso corporal à maturidade sexual em comparação às do grupo B. No entanto, ambos os grupos genéticos apresentam desempenho satisfatório no período de 40 a 124 dias de idade, sendo as aves de ambos os grupos recomendadas como matrizes de codornas de corte.

\section{Literatura Citada}

AKBAR, M.K.; GAVORA, J.S.; FRIARS, G.W. et al. Composition of eggs by commercial sizes categories: effects of genetic group, age, and diet. Poultry Science, v.62, n.6, p.925-933, 1983.

ALMEIDA, M.I.M. Efeito de linhagem e de nível protéico sobre o desempenho e características de carcaça de codornas (Coturnix sp) criadas para corte. Botucatu: Universidade Estadual Paulista, 2001. 96p. Tese (Doutorado em Melhoramento Genético) - Universidade Estadual Paulista, 2001.
ALTAN, O.; OGUZ, I.; AKBAS, Y. Effects of selection for body weight and age of hen on egg characteristics in Japanese quail (Cotunix coturnix japonica). Turkish Journal Veterinary Animal Sciences, v.22, n.6, p.467-473, 1998.

ANTHONY, N.B.; EMMERSON, D.A.; NESTOR, K.E. et al. Divergent selection for body weight and yolk precursor in Coturnix coturnix japonica. 8. A summary of correlated responses. Poultry Science, v.69, n.10, p.1055-1063, 1990.

BACON, W.L.; NESTOR, K.E.; LONG, D.W. Divergent selection for body weight and yolk precursor in Coturnix coturnix japonica. 6. Correlated response in plasma calcium and egg shell traits. Poultry Science, v.65, n.2, p.355-359, 1986.

BARRETO, S.L.T.; PEREIRA, C.A.; UMIGI, R.T. et al. Determinação da exigência nutricional de cálcio de codornas japonesas na fase inicial do ciclo de produção. Revista Brasileira de Zootecnia, v.36, n.1, p.68-78, 2007.

HARMS, R.H.; JUNQUEIRA, O.M.; WILSON, H.R. Specific gravity of turkey and Bobwhite quail eggs as influenced by time of oviposition. Poultry Science, v.62, n.7, p.1325-1326, 1983.

MARKS, H.L. Changes in unselected traits accompanying longterm selection of four-week body weight in Japanese quail. Poultry Science, v.58, n.2, p.269-274, 1979.

MARKS, H.L. Feed efficiency changes accompanying selection for body weight in chickens and quail. World's Poultry Science, v.47, p.197-212, 1991

MASUKAWA, Y.; FERNANDES, E.B.; MORAES, V.M. et al. Níveis de cálcio da dieta sobre o desempenho e a qualidade da casca de ovos de codornas japonesas. ARS Veterinária, v.17, n.2, p.144-148, 2001.

MINVIELLE, F.; MONVOISIN, J.L.; COSTA, J. et al. Long-term egg production egg production and heterosis in quail lines after withinline or reciprocal recurrent selection for high early egg production. British Poultry Science, v.41, n.2, p.150-157, 2000.

MINVIELLE, F.; MILLS, A.D.; FAURE, J.M. et al. Fearfulness and performance related traits in selected lines of Japanese quail (Coturnix coturnix japonica). Poultry Science, v.81, n.3, p.321-326, 2002.

MÓRI, C.; GARCIA, E.A.; PAVAN, A.C. et al. Desempenho e qualidade dos ovos de codornas de quatro grupos genéticos. Revista Brasileira de Zootecnia, v.34, n.3, p.864-869, 2005a.

MÓRI, C.; GARCIA, E.A.; PAVAN, A.C. et al. Desempenho e rendimento de carcaça de quatro grupos genéticos de codornas para produção de carne. Revista Brasileira de Zootecnia, v.34, n.3, p.870-876, 2005b.

MURAKAMI, A.E.; MORAES, V.M.B.; ARIKI, J. et al. Níveis de proteína e energia em rações para codornas japonesas (Coturnix coturnix japonica) em postura. Revista da Sociedade Brasileira de Zootecnia, v.22, n.4, p.541-551, 1993.

NATIONAL RESEARCH COUNCIL - NRC. Nutrient requirements of poultry. 9.ed. Washington, D.C.: National Academy Press, 1994. 156p. 
NESTOR, K.E.; BACON, W.L.; ANTHONY, N.B. et al. Divergent selection for body weight and yolk precursor in Coturnix coturnix japonica. 11. Correlated responses over thirty generations. Poultry Science, v.75, n.4, p.472-477, 1996.

OLIVEIRA, E.G. Pontos críticos no manejo e nutrição de codornas. In: SIMPÓSIO SOBRE MANEJO E NUTRIÇÃO DE AVES E SUÍNOS E TECNOLOGIA DA PRODUÇÃO DE RAÇÕES, 2001, Campinas. Anais... Campinas: 2001. p.71-96.

PICCININ, A. Efeito da interação genótipo-ambiente nas características dos ovos de codornas (Coturnix coturnix japonica) e sua curva de produção. Botucatu: Universidade Estadual Paulista, 2002. 53p. Dissertação (Mestrado em Ciências Biológicas) - Universidade Estadual Paulista, 2002.
RICKLEFS, R.E.; MARKS, H.L. Egg characteristics of lines japanese quail selected for four-week body mass. Poultry Science, v.62, n.6. p.1330-1332, 1983.

SINGH, R.P.; PANDA, B. Effect of seasons on physical quality and component yields of egg from different lines of quail. Indian Journal of Animal Science, v.57, n.1, p.50-55, 1987.

UNIVERSIDADE FEDERAL DE VIÇOSA - UFV. Central de Processamento de Dados (UFV/ CPD). Manual de Utilização do Programa SAEG (Sistema para Análises Estatísticas e Genéticas). Viçosa, MG: UFV, 2004. 59p.

YANNAKOUPOULOS, A.L.; TSERVENI-GOUSI, A.S. Quality characteristics of quail eggs. British Poultry Science, v.27, n.2, p.171-176, 1986. 